\title{
The Grammar of Singapore English Used in Skype Conver sation
}

\author{
M. Aries Taufiq \\ Language Education Science, FBS - Universitas Negeri Padang \\ E-mail:ariespertama@gmail.com \\ Rahmi Eka Putri \\ Master of English Education, FBS - Universitas Negeri Padang \\ E-mail : amethyst.bimekawaii@gmail.com
}

Diterima : 08 Juli $2019 \quad$ Direvisi: 11 November 2019

Diterbitkan : 14 Desember 2019

\section{Abstract}

This article aims at investigating the grammar of conversation occurred among PT. BSI staffs and Cocomas Singapore (CMS) staffs. Since it was a cross-cultural communication, the conversations were mostly taken place via Skype. Most of the time, CMS staffs used Singapore English (Singlish) during the interaction in the workplace while the government of Singapore has encouraged Singaporeans to speak grammatically correct English informal settings such as workplaces. In this article, the researchers analyzed the conversation by describing the grammar used in the Skype conversation. The data were collected from Skype chat history derived from daily conversation among the staffs of BSI and CMS. Then, the data were analyzed and described based on the grammatical characteristics of Singlish proposed by ${ }^{1}$. The findings reveal that the grammatical features of Singlish mostly appeared in the conversations were copula deletion, agreement, and the use of particles. In short, all participants fully utilized Singlish rather than SSE in discussing their work.

Keywords : the grammar of conversation, Singapore English.

\section{Abstrak}

Artikel ini bertujuan untuk menyelidiki tata bahasa percakapan yang terjadi di antara staf PT. BSI dan Cocomas Singapore (CMS). Karena percakapan ini merupakan komunikasi lintas budaya, sebagian besar percakapan dilakukan melalui Skype. Staf CMS menggunakan Bahasa Inggris Singapura (Singlish) selama berinteraksi di tempat kerja sementara pemerintah Singapura telah mendorong warga Singapura untuk menggunakan bahasa Inggris yang benar secara tata bahasa dalam situasi formal seperti ditempat kerja. Pada artikel ini, para peneliti menganalisis percakapan dengan menjelaskan tata bahasa yang digunakan dalam percakapan Skype. Data dikumpulkan dari riwayat obrolan Skype yang berasal dari percakapan harian antara staf BSI dan CMS. Kemudian, data dianalisis dan disajikan berdasarkan karakteristik tata bahasa Singlish yang diusulkan oleh ${ }^{2}$. Temuan mengungkapkan bahwa fitur tata bahasa Singlish sebagian besar muncul dalam percakapan adalah penghapusan kopula, kesepakatan, dan penggunaan partikel. Singkatnya, semua peserta sepenuhnya menggunakan Singlish daripada SSE dalam mendiskusikan pekerjaan mereka.

Kata Kunci: tata bahasa percakapan, Bahasa Inggris Singapura.

${ }^{1}$ J. R. E. Leimgruber, 'Singapore English', 2011.

${ }^{2}$ Leimgruber. 


\section{Introduction}

Grammar is considered as one of the important foundations for communication. People believed that the better the grammar a speaker has, the clearer and the more understood the message will be. That is why speakers tend to pay much attention to their grammar both in written and spoken forms. For this reason, many institutions emphasize the concept of grammar in their teaching process for the students. Various grammar books are available in order to enhance students' grammar ability. Some teachers and instructors even designed their own grammar book based on the students' needs. For example, ${ }^{3}$ designed a textual grammar book and evaluated the book based on the experts' appraisal. This indicates that grammar plays a central role in a language.

However, grammar is often regarded to be less important in spoken language. In a real conversation, many people tend to ignore grammar. They hardly take care of the grammatical rules; they totally forget the grammar while they are speaking. As stated by ${ }^{4}$, the grammar does not help the students in communicating. There are other aspects influencing students in communication. ${ }^{5}$ assert that differences in students' personalities in participating to communication contribute to the communication itself. This implies that the communication process is associated with the personality and behavior of the speakers. In fact, grammar is a part that cannot be separated from the language since the grammar constructs the language.

Thornbury and Slade (2006), in 6 mention two common misconceptions about the grammar of a spoken language. First, it is

\footnotetext{
${ }^{3}$ Roza \& Genta (2018)

${ }^{4}$ Dulay (1982)

${ }^{5}$ Reflianto \& Farida (2018)

${ }^{6}$ Cook \& North (2010)
}

assumed that spoken grammar is the written grammar which is simply realized as speech. Then, spoken grammar is a less complex form of its written corresponding items. It seems that the grammar in spoken language is not as complex as in the grammar in written language.

Thus, spoken grammar continued to occupy an inferior position and seldom deserved a footnote, let alone full-blown description, in either descriptive of pedagogic grammar.

As a result, English spoken grammars are different and vary among English speaking countries, especially for countries whose native language is not English. Since there is no clear standard for grammar used in conversation, it is also influenced by the culture and other languages that exist in those countries. Therefore, there are several kinds of English terms related to in which country the English are used and its dialect. For example, there is American English, which is used in America; British English, which is used in the United Kingdom and Australian English, which is used in Australia.

One of the English varieties commonly discussed and recently popular is Singapore English which is spoken by people in Singapore. Singapore English consists of two forms: Singapore Standard English (SSE) and Colloquial Singaporean English or mostly known as Singlish. SSE is defined as the standard English utilized in Singapore, which is usually applied in more formal settings, such as schools, workplaces and governments. On the other hand, Singlish is an English-based Creole language spoken by the people in Singapore. It consists of various discourse particles and loan words from Malay, Mandarin and Hokkien. ${ }^{7}$ asserts that Singlish is "spoken by a majority of Singaporeans on an

\footnotetext{
${ }^{7}$ Ansaldo (2009)
} 
everyday basis", many of whom are also able to switch between it and SSE. Therefore, it is thus an entire nation of different ethnic affiliations that speaks Singlish and grapples with the 'Singlish problem'.

Singlish is commonly regarded as low prestige in the country and it is not used in formal communication. Since most Singaporeans frequently speak Singlish to their children, children tend to speak Singlish before they speak Standard English. That makes Singlish becomes daily language used in Singapore.

However, the government of Singapore encourages the citizens not to use Singlish as it sees the use of Singlish is a serious problem to deal with. According to ${ }^{8}$, the government launched the Speak Good English Movement (SGEM) to eliminate Singlish from Singaporeans. It is to encourage Singaporeans speak grammatically correct English that is universally understood. Unfortunately, Singaporeans do not positively respond to this movement. Harada states that a recent survey conducted by the SGEM indicates that 41 percent of the respondents thought they do not need to speak good English (The Straits Times, 2008). Thus, this effort does not go well so far. Singaporeans tend to use Singlish in their daily conversation, even in the workplace with a colleague.

As an example, one of the food factories in Padang, whose name is PT. Bumi Sarimas Indonesia (PT. BSI), has a connection with Cocomas Singapore, PTE Ltd (CMS) in Singapore as its marketing team. In dealing with the export issues, PT. BSI staffs communicate with CMS staffs who are Singaporeans, as their partner to discuss the export plans, mostly through Skype. Since it is cross-cultured communication, they use English as the medium. But they tend to use less formal English, though it is in a

\footnotetext{
${ }^{8}$ Harada (2014)
}

workplace. It can be seen from the dictions as well as the grammar of the conversation.

As stated above, Singaporeans use SSE in formal situations such as workplace. In fact, it is still found that there is some speech which used Singlish although they communicate with people from other countries. Therefore, this mini research was conducted to see what kind of English language used by CMS staffs in having conversation with their colleagues. Since it is a mini research, the discussion is limited to the grammar aspects used in Skype conversation among PT. BSI staff and CMS staffs.

The problem of this study is that there are some uses of Singlish during the interaction among one of PT. BSI staffs and CMS staffs in the workplace. It is found that there are many incorrect grammar forms found in the Skype conversations among them. It seems that they do not use SSE for communication. The purpose of this study is to describe what kind of Singapore English used by the staffs in having communication with their colleagues in Indonesia. Furthermore, it also aims to see the grammar used in Skype conversation among one of PT. BSI staff and CMS staff.

\section{Review of Related Theory}

\section{The Grammar of Conversation}

Grammar is an important aspect of spoken language. People will not understand a conversation if the speaker does not have good grammar. However, the grammar used in spoken language is quite different from written language. Therefore, there is no standard form of grammar in spoken language. But it does not mean that there is no grammar in spoken language.

The difference between spoken and written expressions is that the spoken language is simpler that written one. It is because the speakers want to save the time, if 
they use the same grammar as in the written language, the conversation will take a longer time and it will be boring for the speakers. That is why there is some ellipsis in a conversation. In addition, grammar is not only for the sake of the grammar itself, but it is also for the language use of the grammar, especially for conversation.

According to Thornbury and Slade (2006), in ${ }^{9}$, there are some grammatical forms that occur more frequently in conversation.

\section{Complexity}

The grammar in conversation is often simple since it is mostly used in an informal situation. However, Halliday (1985) in Thornbury and Slade (2006), in ${ }^{10}$ argues that "the sentence structure (of speech) is highly complex, reaching degrees of complexity that are rarely attained in writing. This is because the complexity of spoken language is more like that of dance; it is not static and dense but mobile and intricate."

\section{Heads and tails}

They are usually inserted at the beginning of the sentence (head), such as $a$ friend of mine,..., and at the end of the sentence (tail), such as question tags. The head slot consists of a noun phrase that serves to identify key information such as the topic and to establish a common frame of reference for what follows- whether a statement or a question. Thus, the head fulfills a discourse function. While the tail slot is more retrospective in its use, the items are question tags, interrogatives, reinforcement tags, noun phrase identifiers, evaluative adjectives, vague category identifiers, comment clauses.

\section{Grammatical Incompletion}

The problems of spoken language are often ungrammatical, incompletion and

${ }^{9}$ Cook \& North (2010)

${ }^{10}$ Cook \& North (2010) blends. There are several examples of typical incompletions and blends: completion, abandonment, interruption by other speakers and blending.

\section{Ellipsis}

Ellipsis is the deliberate omission of items, such as subject pronouns and verb complements. Ellipsis more frequently occurs at the beginning of utterances rather than in their middle or at their end.

\section{Deixis}

Deixis means using language devices, such as personal pronouns, demonstratives and adverbials.

\section{Tense and aspect}

Tense is used as a grammatical marker of time while aspect is to distinguish between verbal situations that are seen as in progress (or not) or complete (or not). The present tense is by far the most common tense in casual conversation, and the majority of past forms in casual conversation occur in narratives. Moreover, the progressive aspect is found in past narrative and it is relatively uncommon in conversation. Present perfect is often used to comment on changes.

The grammatical forms explained above are the forms that are usually found in spoken language in conversation used by speakers in either British English countries or American English countries.

\section{Singapore English}

Singapore English has become one of the common English varieties discussed currently in the world. Singapore English refers to varieties of the English spoken language in Singapore. There are two main forms of Singapore English - Standard Singapore English (SSE) and Singapore Colloquial English or known as Singlish. Singapore English consists of three sociolects; Acrolect, Mesolect, and Basilect. Both Azilect 
and Mesolect are considered as Standard Singapore English (SSE), while Basilect is considered as Singlish.

SSE is similar to British English in spelling and grammar. It is often used in more polite settings such as the workplace or when communicating with people of higher authority such as teachers, bosses and government officials. SSE is considered to have a higher prestige among society rather than Singlish. SSE is strongly recommended to be used in formal settings. Thus, most educated Singaporeans prefer to use SSE in their daily conversation.

In the other hand, Singapore Colloquial English or Singlish is a variety of spoken English which is very distinct from SSE. Its use is a polarising issue in Singaporean society (Cavallaro, et.al., 2014). Singlish is an Englishbased Creole language spoken in Singapore, which is commonly regarded with low status in Singapore. ${ }^{11}$ asserts that Singlish is very different from the standard one, especially in pronunciation, grammar, and vocabulary. It consists of various discourse particles and loan words from Malay, Mandarin and Hokkien. Singlish is generally considered as low prestige in the country; thus, it is often not spoken in formal situations. The people who usually use Singlish are those who are not fluent in standard English. Singlish is also considered broken English because it causes damage for standard English ${ }^{12}$.

Singlish encounters severe attacks since the government campaigns to eradicate the use of Singlish in society. It has been interdicted from local media and been branded a major obstacle to Singapore's global competitiveness. Regardless of these policies set by the government, most Singaporeans repudiate to renounce the use of this language

11 Leimgruber (2011)

12 Anthea Fraser Gupta, 'Singapore Colloquial English (Singlish)', 2014. as they consider it a symbol of identity and something essential to their integrity. As a result, Singlish is openly spoken everywhere of the city-state; it is increasingly being comprised to television and radio. Most Singaporean today are becoming concerned with the intrinsic values of the language opposing directly to the state as most encounters no difficulties to speak both Standard English and Singlish and to adapt their speech to the required contextual circumstances.

Singlish has become the language chosen by Singaporeans as a way of signifying their national identity. Singlish is believed to be crucial and a cultural icon for Singaporeans on its own right, in spite of how it is considered as a lesser relative of standard English in all senses of the word.

English in Singapore was previously followed by the standard of British English. However, along with the time, the language became independent and was deviated from the standard British English. The English were converted into Singapore English in an autonomous and different language with its own lexical, phonological, or grammatical features.

\section{The Grammar of Singapore English (Singlish)}

The grammar of Singapore English is basically similar to that of other versions of Standard English around the world. Standard Singapore English (SE) is a variety of English that very closely resembles standard British English (StdBrE), while "non-standard" SE is that variety that differs from Standard British English quite a lot. This latter variety is often referred to by many as Singlish. When we hear of complaints about SE, they are generally complaints about Singlish, such complaints 
centre on how divergent the structure of Singlish is from StdBrE ${ }^{1314}$

The definition of grammar in Singapore English is debatable. The linguist's view that grammar refers to the systematicity of language emphasizes equality among languages, from a structural point of view. If we adopt this idea of grammar as systematicity, then SE is grammatical, whether or not we are speaking of Standard Singapore English (SSE) or Singlish, i.e. Colloquial Singapore English (CSE). However, if we look at grammar from the layperson's perspective, where grammar is a code of correct conduct, then we have to be careful which variety we are looking at. SSE would be correct, and thus grammatical, because it does not differ from the standard variety of $\mathrm{StdBrE}$, and it is used by the well-educated, which in Singapore's meritocratic society would naturally constitute the social elite ${ }^{15}$.

The grammar of Singlish is powerfully influenced by other languages and dialects in the region, such as Malay and Chinese, with some structures that are identical to ones in Mandarin and other Chinese languages. As a result, Singlish has acquired some unique features, especially for Basilect. There are some characteristics of the grammar of Singlish. ${ }^{16}$ states several characteristics of Singlish.

\section{Topic Prominence}

Topic prominence highlights the topic of the sentence at the beginning of the sentence. It happens to Chinese and Malay. Topic prominence is considered as operating at utterances and discourse levels. Later, the prominence of the topic can be highlighted by

13 (Alsagoff, 1995, 2010, 2016; Alsagoff, Bao, Pakir, Talib, \& Wee, 1998; C. Tan, 2005;

14 Tan, 2012)

15 Anthea Fraser Gupta, The Step-Tongue: Children's English in Singapore (Cledevon: Multilingual Matters, 1994).

${ }^{16}$ Leimgruber (2011) the insertion of a break or a discourse particle between the topic and the SV clause. This sets the topic apart from the sentence and puts it into a truly prominent position. Often, the topic ends with a rising intonation.

\section{Agreement}

The agreement is usually considered optional in Singlish, like the use of nouns and past tenses. Nouns are possibly marked for plurality; articles are also optional. For example: "He can play piano.", "I like to read a storybook." It is more common to mark the plural by using quantifiers such as "many" and "some" or "four". The tense agreement is kindly variable and not necessary. Ho and Platt (1993) ${ }^{17}$, report various levels of past tense marking, conditioned by phonetics and semantics aspect, with punctual verbs and irregular verbs seeing higher rates of past tense marking. Marking of the past tense often occurs mostly in irregular verbs, as well as verbs where the past tense suffix is pronounced /Id/.

In short, it can be concluded that in Singlish it does not really care about the agreement for each grammatical feature. Singaporeans tend to use nouns in general forms without considering whether they are singular nouns or plural nouns, and so do for verb agreement. The verb agreement is usually happened for past tenses.

\section{Copula Deletion}

The copula refers to the verb "to be" in most varieties of English. It is treated differently in Singlish, as it is found that most verb "to be" are deleted from a sentence. For example: "I damn naughty." And "How come you so late still playing music, ab?"

${ }^{18}$ found that the verb is used least of all when it precedes an adjective phrase and used

${ }^{17}$ Leimgruber (2011)

18 Platt \& Weber (1980) 
most often when the following complement is either a noun phrase or a preposition phrase indicating location. Moreover, according to Leimgruber (2009) ${ }^{19}$, the proportion of verb "to be"-deletion does not even exceed $6 \%$. Therefore, copula deletion, while clearly possible in Singlish, is by no means general. In fact, ${ }^{20}$, in ${ }^{21}$, states that Singlish is opposed to Standard English. The feature itself is Singlish, but not that Singlish requires the features.

\section{Noun Phrase Deletion}

Deleted noun phrases can be found in the subject or the object. This deletion is frequently found even in the formal discourse. For example:

(a) (The book) very cheap, you know.

(b) I don't know why but I like (it/traveling).

The samples displayed above present subject (a) and object (b) deletion. This the common phenomenon found in Singlish; however, it cannot be explained in the same way as in other languages. Based on the samples, it can be seen that once the subject is established, it is unnecessary to repeat it later in discourse.

\section{Inversion}

Inversion is commonly found in interrogatives. As regarded by Gupta (1994). It is the diagnostic of SSE. In wh-questions, Singlish leaves the subject and the verb in the same order as in statements. Moreover, Singlish has the invariant tags is it and or not. The latter frequently co-occurs with can, leading to the emergence of can or not, which can be used as a tag or as a complete utterance, for example:
(a) Your dress new, is it?
(b) Will finish it today or not?

\section{Discourse Particles}

\footnotetext{
${ }^{19}$ Leimgruber (2011)

${ }^{20}$ Gupta (1994)

${ }^{21}$ Leimgruber (2011)
}

The particles used in Singlish are identically similar to Chinese. In general, they are usually found at the end of the sentence. They change the meaning or the tone of the sentence, but not their grammatical meaning. According to ${ }^{22}$, the particles' origins seem to lie in Hokkien and Cantonese. The following are some particles usually used in Singlish and their meaning, though it is not their exact meaning.

Table 1. The particles used in Singlish

\begin{tabular}{|c|c|}
\hline Particles & Meaning \\
\hline $\mathrm{Ah}$ & $\begin{array}{l}\text { Tentative marker, continuation } \\
\text { marker }\end{array}$ \\
\hline Hah & Question marker \\
\hline Hor & Attempts to garner support for a \\
\hline Lah & $\begin{array}{l}\text { preposition } \\
\text { Mood marker }\end{array}$ \\
\hline Leh & Marks a tentative suggestion/ request \\
\hline Lor & Indicates obviousness or resignation \\
\hline $\mathrm{Mah} / \mathrm{ma}$ & Marks information as obvious \\
\hline What/ wot & Marks obviousness and contradiction \\
\hline Meh & Indicates skepticism \\
\hline $\mathrm{Ya}$ & $\begin{array}{l}\text { Convey weak emphasis and } \\
\text { uncontroversially }\end{array}$ \\
\hline
\end{tabular}

All in all, Singlish has different grammar features from other varieties of English. There are so many omissions of the verb "to be" and nouns in the sentence. Singlish also does not consider the past tense form of the verb. What is unique from Singlish is the use of particles. Since it is highly influenced by Chinese culture, the particles found in Singlish are commonly the words borrowed from Chinese languages.

Based on the explanation above, this research focuses on how the grammar of Singlish used during the conversation among colleagues in discussing their jobs at PT. Bumi sarimas Indonesia Padang and Cocomas Singapore. It will be described what are the grammar components exist in the

${ }^{22} \operatorname{Lim}(2007)$

23 Gupta, The Step-Tongue: Children's English in Singapore. 
conversation based on the grammatical characteristics of Singlish proposed by Leimgruber.

\section{Methodology}

This study was conducted to reveal the grammar used in Skype conversations among workers in a cross-cultural setting. To reach the purpose of this study, descriptive analysis research was applied. This kind of research was chosen since the researchers displayed the data as the way they are without any intervention. The participants of this study were three BSI staff who were based in Padang, Indonesia and three CMS staffs who worked in Singapore. The data were collected from Skype chat history derived from the daily conversation among the staff of BSI and CMS. Then, the data were analyzed and described based on the grammatical characteristics of Singlish proposed by ${ }^{24}$. There were several grammar characteristics of Singlish; they were topic prominence, agreement, copula deletion, noun phrase deletion, inversion, and discourse particles. The data obtained in this study were then classified and described based on the grammatical characteristics of Singlish stated previously.

\section{Findings and Discussion}

Based on data analysis, all participants involved in the conversations fully utilized Singlish rather than SSE when discussing their work. The study showed that the characteristics of grammatical features of Singlish mostly found in Skype conversation among PT. BSI staffs and Cocomas Singapore staffs were agreement, copula deletion, and the use of particles. The description of each characteristic is described as follows.

${ }^{24}$ Leimgruber (2011)

\section{Topic Prominence}

In this study, topic prominence is defined as the topic of the sentence which is stated at the beginning of the sentence. One characteristic of Singlish is that the speaker tends to mention the topic of the conversation at the beginning of their talk. This study also found some cases related to topic prominence, for example:

$$
\begin{aligned}
& \text { BSI } 1 \text { : hi Ms Karen } \\
& \text { CMS } 2 \text { :yes } \\
& \text { BSI } 1 \text { : for BI BL, is it ok Ms? } \\
& \text { CMS } 2 \text { :yes, already replied to process } \\
& \text { BSI } 1 \text { : morning Ms Karen } \\
& \text { CMS } 2 \text { :yes monring V anny } \\
& \text { BSI } 1 \text { : for Marsfood shipment } 4 \times 20^{\prime}--> \\
& \text { that shippend on ETD } 30 \text { Sept, Can I have } \\
& \text { PO MArsfood Ms? } \\
& \text { CMS } 2 \text { : how come so many? }
\end{aligned}
$$

From the extract above, it can be seen that the participant mentioned the topic at the beginning of the sentence, which is related to BI BL before delivering the information referring to the topic. Another sample is displayed below.

$$
\begin{aligned}
& \text { BSI } 1 \text { : MS Coreen, for P103921 how } \\
& \text { much is the freight Ms? } \\
& \text { and also P103922 } \\
& \text { CMS } 2 \text { : P103921 is U\$1100.00 } \\
& \text { P103922 is U\$1100.00 }
\end{aligned}
$$

CMS 2 : why we are not informed before hand that you all are schedule $4 \times 20$ ?

We should highlight before it shipped.

BSI 1 : thought you bv in cc before this shipped Ms

CMS 2 : no ade did not mention how many teus. is the bl ready for etd 25 sept?

mars food po: 2004013315, 2004127562,2004134933,200347204 for 30 sept

BSI 1 : the 2 containers is rest from August Ms

Ok, Ms.. for ETD 25 Sept I hv confirm to

Liner.. wait for the payment then $M s$

thanks Ms Karen 
It can be seen that the participant always stated the topic of the sentence first before she wrote the information asked to her colleague. In this conversation, the topic is the order with the code P103921. Based on the samples presented before, it can be stated that topic prominence is not always a noun phrase or subject. It actually refers to the point the participant wanted to say. Thus, topicprominence can be perceived as operating at both utterance and discourse levels. It always comes first, and once it is established, it remains the default topic referred to.

\section{Agreement}

Agreement refers to the use of nouns and past tenses. It is usually considered optional in Singlish. The data demonstrated that there was no wrong agreement for the past tense in the Skype conversation among PT. BSI staff and Cocomas Singapore staff. The past tense verbs were correctly used in the conversation. It can be seen in the following data:

BSI 1 : Morning Ms Coreen
Is Catz, accepted the draft for P103922 just
sent ytd?
CMS 1 : hunt yet
got any original docs courier to us ytd or today?

CMS 2 : I forwarded the BL to buyer by removing the BRIZ already

What $i$ also mean is that this BL is not for BRIZ

you mistake also

The underlined expressions indicate that the participants used the verb correctly to show the past activities. This can also be found in the datum below.

\section{CMS 2 :yup.. I confirmed before you go on leave \\ BSI 1 :ok Ms, please wait. \\ CMS 2 : I didn't receive the draft doc for Navdeepak.}

In this sample, the participant used the correct negative form for the verb receive.

\section{Copula Deletion}

Copula deletion denotes the verb "be" in English variation. The result of data analysis revealed that copula deletion was the feature that was most frequently found in the conversation. The CMS staffs rarely used the verb "to be" during the conversation. It was found that there was almost no verb "to be" in the conversation among BSI staffs and CMS staffs. Moreover, sometimes, they also omitted the subjects in the sentence. For example:

CMS 1 : Hi Ms BSI 1

BSI 1 : ya MS

CMS $1:$ Mr Priyadi not in office?

BSI 1 : yes, in office $M s$

CMS 1 : when shipment schedule for P103922?

BSI 1 :20 Sept Ms.. not received the docs yet Ms?

The samples displayed above showed that the participants omitted "to be" in their sentences. For example, CMS 3 said, $\underline{M r}$ Priyadi not in the office? In this sentence, there should be "to be" is at the beginning of the sentence. Then, in the next sentence, the participant (BSI 1) missed the noun you as the subject.

A similar case is also found in the following samples.

\section{BSI 1 : for BI BL, is it ok $M$ s? \\ CMS 3 :yes, already replied to process \\ BSI 1 : for Marsfood shipment $4 \times 20^{\prime}-$-> that shippend on ETD 30 Sept, Can I have PO Marsfood Ms? \\ CMS 3 : how come so many? \\ BSI 1 :yes Ms CMS 3, we already stuff 4 containers}

The sentences demonstrated that the participant missed the nouns as the subject and also the verb $b e$. 


\author{
CMS $3: B L$ \\ plsplspls \\ BSI 1 : Mr Pri not provide yet Ms? \\ for ETD 15 Sept right Ms? \\ CMS 3 : yes.. Pri said you said liner no \\ around to issue?
}

This sample presents another evidence of the omission of the auxiliary in the sentence. All in all, the data reveal that the participants often omitted the use of the verb to be in their statements.

\section{Noun Phrase Deletion}

The next characteristic of the grammar of Singlish is noun phrase deletion. Data of this study demonstrated that the participants (CMS staffs) frequently deleted the noun or noun phrase, especially the noun as a subject. The data related to this characteristic is displayed below.

CMS 1 : got any original docs courier to us
ytd or today?
BSI $1 \quad$ : tomorrow will courier all original
$\begin{array}{ll}\text { docs } M s & \\ C M S 1 & \text { :ok ths } \\ B S I 1 \quad: \text { ok } M S\end{array}$

From this conversation, it can be seen that the underlined sentence does not contain a subject. As stated there, the participant, who is actually an Indonesian, wrote, "tomorrow will courier all original docs Ms". Actually, she would like to say that she would send all the original documents the next day. It also occurred to the conversation presented below:

CMS 2 : bi morning BSI 1
BSI 1 : morning CMS 2
CMS 2 :just want to check whether BSI 3
around?
BSI 1 : yes Ms, he is on the phone
CMS 2 : ok, after he offline ask bim to
skype me. Thanks

BSI 1 : yes Ms Karen, we already stuff 4 containers would you like to advise the Marsfood Po Ms? CMS 2 : why we are not informed before hand that you all are schedule $4 \times 20$ ?

We should highlight before it shipped.

BSI 1 : thought you bv in cc before this shipped $M s$

CMS 2 : no ade did not mention how many teus. is the bl ready for etd 25 sept?

mars food po: 2004013315, 2004127562,2004134933,200347204 for 30 sept

BSI 1 : the 2 containers is rest from August Ms

Ok, Ms.. for ETD 25 Sept I bv confirm to Liner. wait for the payment then $M s$

thanks Ms Karen

These samples indicated by the underlined sentences are in line with the previous sample, in which the participant also deleted the subject of the underlined sentence.

below:

Another sample is presented

CMS 1 : Hi Ms Vanny

BSI 1 :yes Ms Coreen

CMS 1 : DN \& CN for P101359,

P103930, P103929, P101201 \& P103921

BSI 1 : have courier on Sat Ms

bope today can received

CMS 1 : ok.. I check later if docs rec from DHL

BSI $1 \quad:$ ok $M s \backslash$

The underlined sentences above also show that the participant omitted the noun in the position of the subject of the sentences. Based on the samples, it was revealed that most of the time she omitted the noun in the position of the subject. It implies that noun phrase deletions frequently occur even informal discourse.

\section{Inversion}

The next grammatical feature found in the conversation is inversion. As stated in the previous section, inversion refers to the order 
of subject and verb in interrogatives which are constructed similar to the order in the statement. In other words, the interrogative statement in Singlish has similar pattern to the statement. It may trigger any ambiguity since this was a written conversation in which the participants could not hear the speaker's intonation. The samples are presented below.

BSI 1 : CMS 3, for Davis Trading shipment for ETD 05/ oct --> using 2

PO.. Is the docs combine or split Ms?

CMS 3 : let me check with them and revert tomorrow can?

and you own me CN/DN for Ang Davis Trade

In this conversation, the participant inverted the position of modal to the end of the sentence. In fact, the statement is interrogative but it sounds more like question tag.

BSI 1 : yes Ms Karen, we already stuff 4 containers

would you like to advise the Marsfood Po Ms?

CMS 2 : why we are not informed before hand that you all are schedule $4 \times 20$ ?

We should highlight before it shipped.

BSI 1 : thought you bv in cc before this shipped $M s$

CMS 2 : no ade did not mention how many teus. is the bl ready for etd 25 sept?

mars food po: 2004013315, 2004127562,2004134933,200347204 for 30 sept

BSI 1 : the 2 containers is rest from August Ms

Ok, Ms.. for ETD 25 Sept I bv confirm to

Liner. wait for the payment then $M s$

thanks Ms Karen

A similar case also is also found in the samples above. The participant wrote a statement but put a question mark at the end of the sentence. This concludes that she actually wanted to ask something rather than telling something. However, grammatically her sentence follows the rules for positive statement.

In addition to the order of subject and verb in interrogatives, inversion is also characterized by invariant tags is it and or not, can, and or. For example:

BSI 1 : Ms, sorry.. Can I have BSI inv number to make easier to find the data $M s$

CMS : u mean the on or dn?

BSI 1 :yes ms

BSI Inv number

$C N n$ DN not yet provide

BSI 1 : morning Ms Coreen

Is Catz accepted that the draft for P103922 just sent ytd?

CMS 1 : bunt yet

got any original docs courier to us ytd or today?

BSI 1 : tomorrow will courier all original $\operatorname{docs} M s$

CMS 1 : ok thes

BSI 1 :ok MS

The samples presented above show the illustration of how the participants used inversion in the conversation. The samples demonstrate that the participant used invariant tags or in the sentence.

\section{Discourse Particles}

The last grammatical feature found in the conversation was discourse particles. Discourse particles usually appear at the end of the utterances. Based on the results of data analysis, the common particles used in the conversation among the staffs are leh, aiyo, ma, and hiaz. However, the most frequently used discourse particles in the conversation were leh and ma. For example:

CMS 1 : navdee using their own liner $i$ don't care behehe

BSI 1 : Wait, Lambda --> not yet know the freight? have been shipped leh

CMS 1 : Is the balance 2 containers my dear dear? 
From this conversation, the particle used by the participant is leh indicating a mood marker that something has been done so there is no need to worry.

Another example is displayed below.

CMS 3 : habaha. so big reaction

BSI 2 :(facepalm)

CMS 3 : Ade also nice ma Hahaha

Zaimul? hahaha... Zaimul very nice too $\underline{\text { ma }}$

In this conversation, the particle ma indicates that the information stated by CMS 3 is clear so she thinks BSI 2 does not need to argue. However, in this conversation both participants were not discussing about their jobs.

CMS 1 : $u$ bunt forward me the shipping docs for this one right

BSI 1 : so sorry

CMS 1 : no bunt rec

BSI 1 : the Seal in the BL is still not indicate yet

I will provide by today, ok $M s$ ?

CMS 1 : aiyo... can u forward me the sailing schedule for P103578

BSI 1 :ya Ms.. already sent

Form this conversation, it can be seen that the participant used a discourse particle "aiyo" which indicates an expression of unbelieve because her colleague did not provide the documents she required.

Based on the results of data analysis, it was found that the conversation occurred among BSI and CMS staffs really reflects the characteristics of grammar of Singlish. The data show that the characteristics of grammar of Singlish found in the conversation between BSI staffs and CMS staffs are topic prominence, agreement, copula deletion, noun phrase deletion, inversion, and discourse particles. It can be seen from the findings presented previously that all features of the grammar of Singlish are found in the conversation although some of the participants are not Singaporean (they are Indonesian). The results of this study confirm that CMS staffs still prefer to use Singlish rather than standard English even in the office when working with their colleague.

The findings of this study reveal that the staffs mostly used Singlish during their communication in discussing the work although they are in a formal situation. Even, BSI staffs also used Singlish although they are Indonesian. From the data analysis, it was found that there were numerous deletions of the verb 'to be' in the conversation. Besides, most of the time, the participants missed the subjects in their utterances. It was also found the frequent use of "can" and "right" (at the end of the sentence to indicate interrogatives) which are totally different from the standard version of English. This kind of conversation would cause some misunderstanding for the readers since the context was not clearly described. It was arduous to discriminate statements and interrogatives in Singlish. Moreover, the participants often forgot to use punctuations in their conversation.

The findings of this study refute the statement from ${ }^{25}$ that Singlish is restricted to informal situations while Singaporeans should use SSE in formal situations. This implies that the workers should not utilize Singlish in workplace. As stated by ${ }^{26}$, the government of Singapore initiated Speak Good English Movement (SGEM) in order to eliminate Singlish from the Singaporeans. It aims to encourage Singaporeans to speak grammatically correct English so that it can be universally understood. Indeed, a good amount of work has appeared since then to provide further evidence of the rule-governed and sociolinguistically legitimate nature of Singlish 27

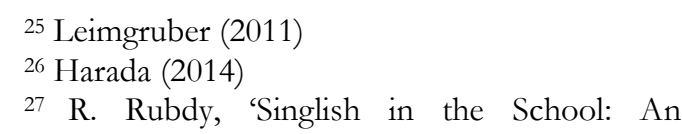
Impediment or a Resource?', Journal of Multilingual and 
Moreover, ${ }^{28}$ adds that SGEM was established to substitute the tendency of using Singlish in everyday communication since Singaporeans frequently speak Singlish in their life. Hence, Singlish is considered as "broken English" by the leaders of government. This statement is supported by the results of data analysis of this study which confirmed that Singlish appears to be grammatically mess, compared to the Standard English.

Related to the fact that the staffs of CMS prefer to use Singlish rather than SSE, a study conducted by ${ }^{29}$ found that not all Singaporeans accept this movement. The Straits Times (2008) demonstrated a survey conducted by the SGEM, finding that almost half of the respondents thought that they did not need to speak good English. This implies that Singlish associates the people to their community and is an active part of most Singaporeans. Singlish is a fundamental element as an inter-ethnic lingua franca in Singapore ${ }^{30}$. Thus, the rule of SGEM seems to be failed because it ignores the relationship between language and identity.

Furthermore, Singapore became an "English-knowing" multilingual country with the local languages, especially the official mother tongues, still widely entrenched in the linguistic repertoire of individual speakers ${ }^{31}$. Thus, ${ }^{32}$ describes that Singlish is neither the result of learning bad English nor a deliberate destructive effort. In fact, Singlish should be

Multicultural Development, 28.4 (2007), 308-24; C. J. Sato, 'A Nonstandard Approach to Standard English', TESOL Quarterly, 23.3 (1989), 68-91.

${ }^{28}$ Echaniz (2015)

${ }^{29}$ Echaniz (2015)

${ }^{30} \mathrm{~L}$. Wee, 'Intra-Language Discrimination and Linguistic Human Rights: The Case of Singlish', Applied Linguistics, 26.1 (2005), 48-69; Harada.

31 A. Pakir, 'English-Knowing Bilingualism in Singapore', in Imagining Singapore, ed. by K. C. Ban, A. Pakir, and C. K. Tong (Singapore: Times Academic Press, 1992), pp. 234-362; A. Pakir, 'The Range and Depth of English Knowing Bilinguals in Singapore', World Englishes, 10.2 (1991), 167-179.

${ }^{32}$ Fong, Lim, \& Wee, (2002) \& Wee (2009) considered as a valuable cultural treasure instead of an obstacle to achieve progress, as the SGEM defends. Because English in Singapore is influenced by many cultures, Singlish (the localized English in Singapore) has its own history. Thus, Singlish becomes unique on its own.

Finally, it is worth to note that this kind of conversations would cause any confusing perception if the readers do not read the complete conversation. It means that the ones who completely understand this conversation are the people involved in it. This situation braces the fact that Singapore Colloquial English (Singlish) is unique and has its own rule.

\section{Conclusions}

This study reveals that the conversation occurred among the staffs was dominated by Singlish although they were discussing about their work in a formal setting. BSI staffs, who were Indonesians, also got influenced by CMS to use Singlish. Based on the result of data analysis, there are some topic prominences in the conversation. First, the subjects and the verb "to be" were frequently omitted. It also happened to interrogative utterances. Then, the use of discourse particles was also found to be frequent in the conversation. In short, it can be asserted that the influence of Malay and Chinese was obviously influence the conversation, which should use the standard English and be more formal. It is hoped that this study gives a contribution to the language users about varieties in English language.

\section{References}

Alsagoff, Lubna, 'Colloquial Singapore English: The Relative Clause Construction', in The English Language in Singapore: Implications for Teaching, 1995, pp. $77-87$

- 'English in Singapore: Culture, 
Capital and Identity in Linguistic Variation', World Englishes, 29.3 (2010), 336-48

, 'Interpreting Error Patterns in a Longitudinal Primary School Corpus of Writing', The Asian Journal of Applied Linguistics, 3.1 (2016), 114-24

Alsagoff, Lubna, Z. Bao, A. Pakir, I. Talib, and L. Wee, The Grammar of Singapore English: Society, Style and Sturcture in Language (Singapore: Prentice Hall, 1998)

Ansaldo, U., 'The Asian Typology of English: Theoretical and Methodological Considerations', English World-Wide, 30.2 (2009), 133-48

Cook, Guy, and Sarah North, Applied Linguistics in Action: A Reader (New York: Routledge, 2010)

Dulay, Language Two (New York: Oxford University Press, 1982)

Echaniz, Markel Echeverria, 'English as a Contact Language: Singapore English' (Universidad del Pais Vasco, 2015)

Fong, V., L. Lim, and L. Wee, "'Singlish": Used and Abused', Asian Englishes, 5.1 (2002), 18-39

Gupta, Anthea Fraser, 'Singapore Colloquial English (Singlish)', 2014 , The Step-Tongue: Children's English in Singapore (Cledevon: Multilingual Matters, 1994)

Harada, Shinichi, 'The Roles of Singapore Standard English and Singlish', 2014

Leimgruber, J. R. E., 'Singapore English', 2011

Lim, Lisa, 'Mergers and Acquisition: On the Ages and Origins of Singapore English Particles', World Englishes, 26 (2007), 446-473

Pakir, A., 'English-Knowing Bilingualism in Singapore', in Imagining Singapore, ed. by K. C. Ban, A. Pakir, and C. K. Tong (Singapore: Times Academic Press, 1992), pp. 234-362

, 'The Range and Depth of English Knowing Bilinguals in Singapore', World
Englishes, 10.2 (1991), 167-179

Platt, John T., and Heidi Weber, English in Singapore and Malaysia: Status, Features, Functions (Oxford: Oxford University Press, 1980)

Reflianto, and A. Farida, 'Conscientiousness and Emotional Stability on Students' Speaking Ability through Flipped Classroom', Jurnal Educative: Journal of Educational Studies, 3.2 (2018), 137-49

Roza, V., and S. Genta, 'Expert Appraisal on Islamic Textual Enhancement Grammar Book Designed for Grammar Teaching at IAIN Bukittinggi', Jurnal Educative: Journal of Educational Studies, 3.2 (2018), 150-65

Rubdy, R., 'Singlish in the School: An Impediment or a Resource?', Journal of Multilingual and Multicultural Development, 28.4 (2007), 308-24

Sato, C. J., 'A Nonstandard Approach to Standard English', TESOL Quarterly, 23.3 (1989), 68-91

Tan, C., 'English or Singlish? The Syntactic Influences of Chinese and Malay on the Learning of English in Singapore', Journal of Language and Learning, 3.1 (2005), 156-79

Tan, P. K. W., 'English in Singapore', International Journal of Language, Translation and Intercultural Communication, 1 (2012), 123-38

Wee, L., 'Intra-Language Discrimination and Linguistic Human Rights: The Case of Singlish', Applied Linguistics, 26.1 (2005), 48-69

, 'Singapore English: Morphology and Syntax', in Varieties of English: Africa, South and Southeast Asia, ed. by Rajend Mesthrie (Berlin: Mouton de Gruyter, 2009), pp. 593-609 